\title{
Electrophysiological correlates of the perceptual fluency effect on recognition memory in different fluency contexts
}

Wei Wang ${ }^{\mathrm{a} *}$, Bingbing $\mathrm{Li}^{\mathrm{b}}$, Mingzhu Hou ${ }^{\mathrm{c}}$, Michael D. Rugg ${ }^{\mathrm{cd}}$

${ }^{a}$ MOE Key Laboratory of Modern Teaching Technology, Shaanxi Normal University, Xi'an, 710062, PR China

${ }^{\mathrm{b}}$ School of Education Science, Jiangsu Normal University, Xuzhou, 221116, PR

China

${ }^{\mathrm{c}}$ Center for Vital Longevity, University of Texas at Dallas, Dallas, 75235, USA

${ }^{\mathrm{d} S c h o o l ~ o f ~ P s y c h o l o g y, ~ U n i v e r s i t y ~ o f ~ E a s t ~ A n g l i a, ~ N o r w i c h, ~ N R 4 ~ 7 T J, ~ U K ~}$

* Corresponding author

Wei Wang

MOE Key Laboratory of Modern Teaching Technology

Shaanxi Normal University

No.199 South Chang'an Road

Yanta District, Xi'an, 710062

PR China

$+86-185-9199-1316$

humphrydavy@snnu.edu.cn 


\begin{abstract}
The present study used event-related potentials (ERPs) to investigate the contribution of perceptual fluency to recognition memory in different fluency contexts. In a recognition memory test with a modified remember-know paradigm, we employed conceptually impoverished items (kaleidoscope images) as stimuli and manipulated the perceptual fluency of recognition test cues through masked repetition priming. There were two fluency context conditions. In the random fluency context (RC) condition, primed and unprimed trials were randomly inter-mixed. In the blocked fluency context (BC) condition, primed and unprimed trials were grouped into blocks. Behavioral results showed that priming elevated the incidence of remember hits and the accuracy of remember judgements in the RC condition; no such effects were evident in the $\mathrm{BC}$ condition. In addition, priming effects on reaction times were found only for remember hit responses in the RC condition. The ERP results revealed an early100-200 ms effect related to masked repetition priming, which took the form of greater positivity for primed than unprimed trials. This effect was modulated neither by fluency context or response type. The present findings suggest that perceptual fluency induced by masked repetition priming affects recollection-related memory judgments in a specific fluency context and indicate that relative, rather absolute, fluency plays a critical role in influencing recognition memory judgments.
\end{abstract}

Keywords: perceptual fluency, recognition memory, fluency context, ERP 


\section{Introduction}

Fluency, which is typically defined as the speed and ease of processing (for review, see Oppenheimer, 2008), has been linked with recognition memory judgments. It has consistently been reported that fluently processed recognition test items have an elevated tendency to be endorsed as "old" even when unstudied (e.g., Jacoby \& Whitehouse, 1989; Westerman, Lloyd, \& Miller, 2002; Westerman, Miller, \& Lloyd, 2003; Whittlesea, Jacoby, \& Girard, 1990). According to dual-process models, recognition memory performance is dependent on two distinct processes, recollection and familiarity (for review, see Yonelinas, 2002) and the findings of numerous studies suggest that enhanced fluency selectively impacts familiarity-based recognition judgements (e.g., Lucas, Taylor, Henson, \& Paller, 2012; Rajaram \& Geraci, 2000; Westerman, Lanska, \& Olds, 2015; Woollams, Taylor, Karayanidis, \& Henson, 2008). However, in some studies it was reported that recollection can also be affected by fluency manipulations (Li, Taylor, Wang, Gao, \& Guo, 2017; Park \& Donaldson, 2016; Taylor, Buratto, \& Henson, 2013; Taylor \& Henson, 2012; Wang, Li, Gao, \& Guo, 2018; Wang, Li, Gao, Xu, \& Guo, 2015).

Among studies linking fluency and recognition memory, the most common method employed to manipulate fluency is masked repetition priming, first used by Jacoby and Whitehouse (1989). With this method, recognition test items are preceded by a brief, masked prime item that either matches or does not match the test item. The probability of old responses increases when the masked prime item matches the test item, regardless of whether the test item is studied or unstudied. This effect has often been attributed to a priming related enhancement of perceptual fluency (e.g., Johnston, Hawley, \& Elliott, 1991; Rajaram, 1993). In addition, researchers have used masked conceptual priming to manipulate conceptual fluency and have reported that conceptual fluency can also modulate recognition memory judgements (e.g., Rajaram \& Geraci, 2000; Taylor \& Henson, 2012).

ERPs (event-related potentials) have proven to be a valuable tool for investigating the neural correlates of different memory processes. For example, Rugg, et al. (1998) reported that distinct ERP components were associated with implicit and explicit 
memory in a single recognition memory test. Findings from numerous studies of recognition memory suggest that familiarity and recollection are indexed by two different ERP components, known as the FN400 (mid-frontal old/new effect) and LPC (late positive complex) respectively (e.g., Bridger, Bader, Kriukova, Unger, \& Mecklinger, 2012; Curran, 2000; Curran \& Cleary, 2003; Rugg \& Curran, 2007). However, some researchers have proposed the alternative interpretation that the FN400 reflects conceptual priming (e.g., Gao, Hermiller, Voss, \& Guo, 2015; Hou, Safron, Paller, \& Guo, 2013; Paller, Voss, \& Boehm, 2007; Voss \& Federmeier, 2011). In one study (Bridger, Bader, \& Mecklinger, 2014), the FN400 was reported to be dissociable from a more posteriorly distributed ' $N 400$ '. The authors proposed that while the FN400 was a neural correlate of the relative familiarity of a test item (the 'additional' familiarity gained from a recent study exposure), the N400 was a correlate of an item's 'absolute' familiarity. Researchers have combined ERPs with the Jacoby and Whitehouse (1989) paradigm to examine the relationship between fluency and recognition memory. For example, Woollams, et al. (2008) reported that masked repetition was associated with both an early centrally-focused ERP effect and a later, more posteriorly distributed modulation of N400. By contrast, Lucas, et al. (2012) and Park and Donaldson (2016) were able to identify only the posterior N400 component when using a similar paradigm.

Of importance, relative rather than absolute fluency is thought to play the major role in influencing recognition memory judgments. For example, Westerman (2008) reported that the fluency effect on recognition memory is modulated by the fluency of surrounding test items. In a series of behavioral experiments, Westerman (2008) manipulated the proportion of primed words in a recognition memory test, and found that fluency impacted recognition judgments to a greater extent when there was a relatively low proportion of primed test items compared to when most of the test trials were primed. In a pioneering study, Leynes and Zish (2012) employed ERPs to investigate the role of 'fluency context' in recognition memory. The researchers manipulated perceptual fluency by presenting half of the test items in a blurred format, and the remainder in a clear format. In one condition, the clarity of the test words varied 
randomly across trials. In a second condition, the fluency manipulation was blocked. Whether the fluency manipulation was randomized or blocked led to different findings for both behavioral and ERP measures. Specifically, clear items gave rise to a higher hit rate than blurred items, and the FN400 old/new effect was observed only when clarity was varied randomly. In contrast, in the blocked condition memory accuracy was not affected by clarity and the fluency manipulation was associated with an earlier ERP component (280-400 ms). The authors suggested that the different patterns of findings resulted from the distinct fluency 'contexts' created by the random and blocked conditions. That is, fluency impacted recognition judgments when it varied randomly across trials, causing the test items to differ in their relative fluency. By contrast, when the fluency manipulation was blocked items within a block differed little in their relative fluencies and hence fluency could no longer serve as a basis for the recognition judgments. In two subsequent studies, a similar paradigm was used to investigate the influence of perceptual fluency on recognition memory (Bruett \& Leynes, 2015) and mere exposure effects (Leynes \& Addante, 2016). The results suggested that fluency context plays a key role in the contributions of fluency to both memory and affective judgements.

In a more recent study, Gomes, Mecklinger, and Zimmer (2017) employed the Leynes and Zish (2012) paradigm in a functional magnetic resonance imaging (fMRI) experiment, using masked repetition priming to manipulate fluency. They reported different behavioral fluency effects and distinct neural correlates of fluency in random and blocked context conditions. In the random context (RC) condition, masked repetition priming only affected recognition memory accuracy for high confidence responses. By contrast, in the blocked context (BC) condition, priming effects on behavior were not observed. In addition, the RC and $\mathrm{BC}$ conditions demonstrated different neural correlates of masked priming. Specifically, in the RC condition, there was an increased activity in several occipitotemporal and frontal regions for primed trials relative to unprimed trials, whereas in the $\mathrm{BC}$ condition, decreased activity was identified in the right middle frontal gyrus, precuneus and putamen for primed relative to unprimed trials. Furthermore, the size of the behavioral priming effect in the RC 
condition (calculated as the difference in recognition memory accuracy (hit rate minus false alarm rate) between primed and unprimed high confidence trials) correlated positively with the fMRI priming effects (unprimed high confidence hits minus primed high confidence hits) in left parietal and posterior cingulate cortex.

Of importance, repetitions of meaningful stimuli, such as words, can give rise concurrently to perceptual priming for the physical features of a word and conceptual priming for its meaning (Voss, Schendan, \& Paller, 2010). In a previous study conducted in our laboratory (Wang, Li, Gao, Xiao, \& Guo, 2015), we identified distinct ERP correlates of perceptual and conceptual fluency. In a recognition memory test that was combined with the masked repetition paradigm, Chinese pictographic characters were categorized as high or low meaningfulness on the basis of subjective ratings. We hypothesized that priming of low meaningfulness (Low-M) items would enhance perceptual fluency, while priming of high meaningfulness (high-M) items would enhance both perceptual and conceptual fluency. The results indicated that masked repetition priming enhanced both perceptual and conceptual fluency, and that these fluency effects were reflected by ERP effects with different onset latencies and durations: a 150-250 ms effect for low meaningful primed items compared to unprimed trials as opposed to a 300-500 ms effect for highly meaningful primed items compared to unprimed trials. These findings suggest that the effects of perceptual fluency on recognition memory are confounded with conceptual fluency when repetition priming is employed to manipulate the fluency of meaningful stimuli.

The aim of the present study was to further examine the impact of masked repetition priming on recognition memory using ERPs. To restrict fluency effects to the perceptual realm, we employed conceptually impoverished items - kaleidoscope images - as the experimental items. Kaleidoscope images have been used in prior studies to minimize the influence of conceptual processing in memory tests. For example, Voss and Paller (2009b) used kaleidoscope images to characterize neural correlates of the familiarity of meaningless stimuli in a recognition memory test. No FN400 old/new effect was observed for the correctly recognized items endorsed 'Know', leading the authors to suggest that modulation of the FN400 is a reflection of 
conceptual implicit memory rather than familiarity. In another study with kaleidoscope images, faster and more accurate color judgments were reported for repeated items relative to new items, and this behavioral priming effect was accompanied by a negative-going ERP effect in the 100-300 ms latency range (Voss \& Paller, 2010).

In the present experiment, we used a modified remember/know $(\mathrm{R} / \mathrm{K})$ paradigm to assess the contributions of recollection and familiarity to recognition memory judgments. The modification was motivated by the findings of a previous study in which it was reported that masked repetition priming selectively influenced 'guess' responses (Tunney \& Fernie, 2007). Accordingly, here we added a "guess" option to the standard R/K procedure. Voss and Paller (2009a) used a similar paradigm and reported that guess responses were surprisingly accurate in a forced-choice test and that between 200-400 ms post-stimulus, ERPs elicited by old items endorsed as guesses were more negative-going than the ERPs elicited by new items attracting a guess judgement. The authors described this phenomenon as "implicit recognition" and speculated that it was supported by perceptual fluency. If, in the present study, we find an effect of perceptual fluency on guess judgments, this might provide direct evidence for this proposal.

We employed a paradigm similar to that utilized by Leynes and Zish (2012) to manipulate fluency context. Primed and unprimed trials were randomly varied within each block in the random fluency context $(\mathrm{RC})$ condition, and were presented in separate blocks in the blocked fluency context (BC) condition. Based on the findings of Leynes and Zish (2012) and Gomes, et al. (2017), we predicted that behavioral effects of the perceptual fluency manipulation would be confined to the RC condition. In addition, movitated by our prior ERP findings that enhanced perceptual fluency was associated with a more positive early ERP component (Wang, et al., 2018; Wang, Li, Gao, Xiao, et al., 2015), we predicted that an early ERP correlate of differential perceptual fluency would also be evident in the RC condition only.

\section{Materials and methods}




\subsection{Participants}

Forty-eight participants (aged 18-23 years, 7 males) participated in the experiment (24 in each fluency context, allocated by random assignment). All participants were right-handed and reported normal or corrected to normal vision. Each participant signed an informed consent form and received monetary compensation. The study was approved by the local ethics committee.

\subsection{Materials}

320 kaleidoscopic pictures, corresponding to those originally used by Voss and Paller (2009b) were selected as stimuli. The primed/unprimed and old/new status of the stimuli sets were counterbalanced across participants. Another 40 kaleidoscope pictures were used in filler trials.

\subsection{Procedure}

There were eight study-test blocks in each fluency context condition, with fluency context condition as a between subjects manipulation. In each study phase, 20 pictures were presented in a random order, with two filler pictures presented at the beginning and the end of the phase to avoid primacy and recency effects. Participants were instructed to focus on the color and shape of each picture and to memorize it. In each test phase, the participants completed a recognition memory test in which 20 old pictures from the immediately preceding study phase were intermixed with 20 new pictures.

Perceptual fluency was manipulated in the test phase. There were 20 items $(10$ old, 10 new) in each of two categories: primed (i.e., an old or new item that was preceded by a masked presentation of the same item), and unprimed (i.e., an old or new item that was preceded by masked presentation of a different item (either studied or unstudied) from the same test block). In the random fluency context (RC) condition, primed and unprimed trials were randomly inter-mixed in each test block. In the blocked fluency context (BC) condition, primed and unprimed trials were presented in separate blocks, that is, four blocks contained only primed trials, and another four blocks contained only 
unprimed trials. The order of the primed and unprimed blocks was alternated and counterbalanced across participants. Stimuli were presented at the center of an LED computer screen (refresh rate $60 \mathrm{~Hz}$ ) positioned approximately $70 \mathrm{~cm}$ in front of the participant. Stimuli subtended visual angles of approximately $5^{\circ} \times 5^{\circ}$.

In the study phase, each trial began with a fixation cross presented for a random duration that varied 1000 and $2000 \mathrm{~ms}$, which was followed by a picture for $1500 \mathrm{~ms}$ and then another fixation cross. The test phase followed the study phase in each block after a break of 30s, during which the participants counted backward by threes. Each test trial began with a fixation cross that lasted for a random duration between 1500 and $2500 \mathrm{~ms}$. A forward mask was then presented for $500 \mathrm{~ms}$, followed by a primed or unprimed picture for $50 \mathrm{~ms}$, followed immediately by a backward mask for $50 \mathrm{~ms}$. The test picture was then presented for $1000 \mathrm{~ms}$, followed by a $1500 \mathrm{~ms}$ blank screen (Figure $1)$.

The participants were instructed to indicate whether they had seen the test picture in the study phase by responding old (seen) or new (not seen). Both speed and accuracy of response were emphasized. If they responded old, participants were prompted to indicate whether they 'remembered' the test picture ("R" judgment), felt that the picture was familiar ("K" judgment) or had just guessed the picture was old ("G" judgment). If participants responded 'new', or failed to respond within $1500 \mathrm{~ms}$, the next test trial began. Participants were instructed that if they could recall any contextual details associated with the test items (e.g., their feelings when they studied the picture), they should make an " $R$ " judgment. If they believed that the picture had been encountered in the study phase but they could not recall any contextual information, instructions were to make a "K" judgment. In the absence of any sense of familiarity for the test item, they were instructed to make a " $G$ " judgment. Assignment of response buttons to the different judgments was counterbalanced between participants.

Prior to the experiment proper, there were two short practice blocks. Each block contained 10 study and 20 test trials. In some practice test trials, participants were asked to report the subjective bases of their "R", "K", or "G" judgments were made. This was done to ensure that they had correctly understood the instructions and did not equate 
$\mathrm{R} / \mathrm{K}$ responses with high/low confidence ratings.
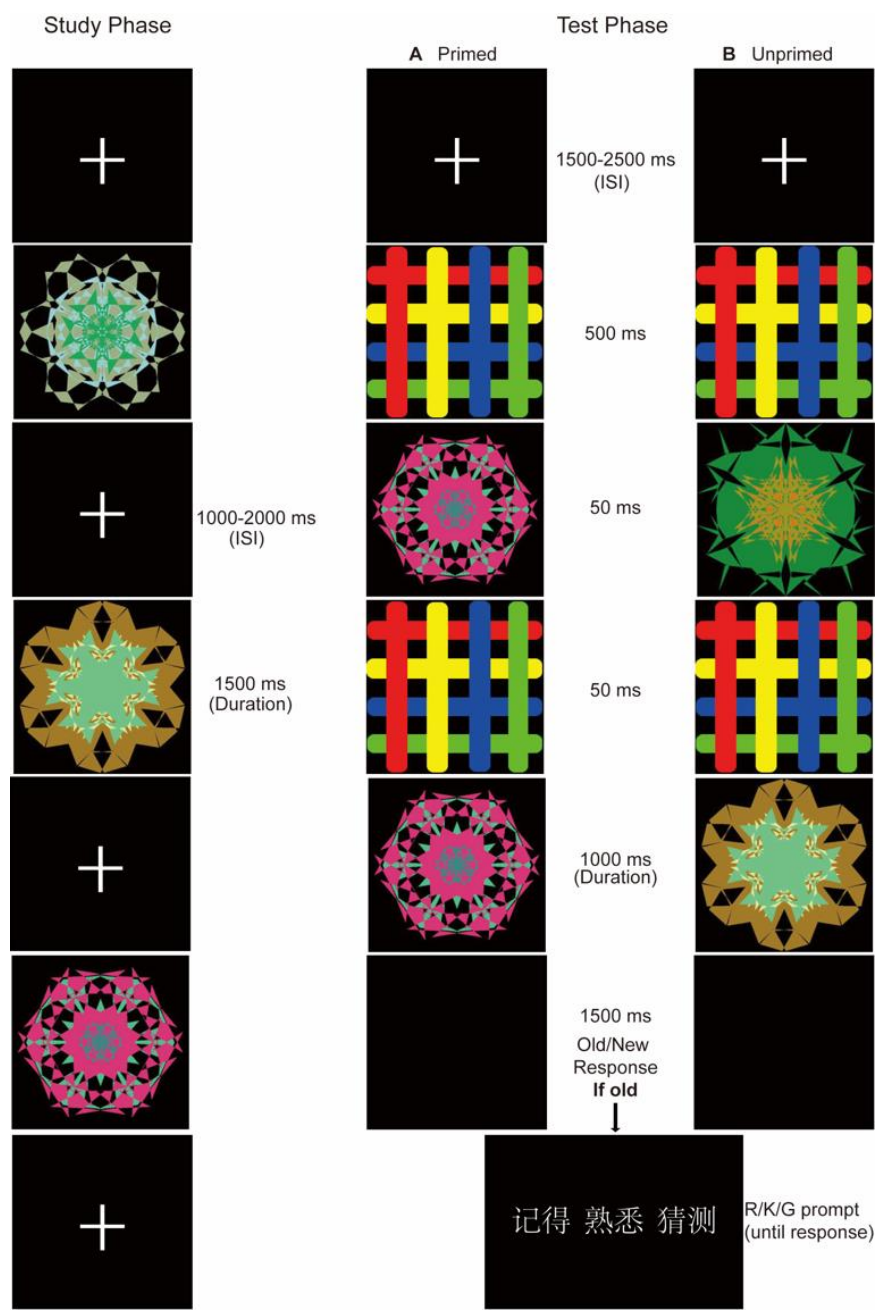

Figure 1. The schematic of trial procedure for both conditions, showing examples of the stimuli. (A) primed trials, a test item that was preceded by masked presentation of the same item. (B) unprimed trials, a test item that was preceded by masked presentation of a different item (either studied or unstudied) that occurred in the same block.

Participants were not informed about the presence of the masked pictures during the test phase. Rather, they were told that the symbols (forward mask) were used to "prompt" the appearance of the test pictures and that, in order to achieve the best memory performance, they should focus on the test pictures. After completion of the eight study-test blocks, the experimenter thanked and debriefed each participant. They were asked whether they had noticed something presented between the "prompt" and the following test picture. In addition, the experimenter re-presented the test phase of 
the practice block and asked the participants to pay attention to the "flickers" between the "prompt" and test picture. Again, the participants were asked to identify the "flickers" and reported the relationship between the "flickers" and the following test picture.

All of the 48 participants reported that they were unable to recognize the masked pictures, although they noticed there were some "flickers" before the target in some test trials. When the experimenter presented the test procedure again, 15 of the 48 participants reported that the "flickers" were kaleidoscope pictures similar to the test items. Three of them reported that occasionally these were same as the later test items.

\subsection{Electrophysiological recording and analyses}

Event-related potentials were extracted from scalp electroencephalographic recordings obtained from $62 \mathrm{Ag} / \mathrm{AgCl}$ electrodes embedded in an elastic cap. The electrode locations adhered to the extended international 10-20 system. All channels were referred online to the left mastoid. Signals were re-referenced offline to averaged mastoids. Four additional channels were used for monitoring horizontal and vertical eye movements. Electrode impedance was kept below $5 \mathrm{k} \Omega$. EEGs were continuously recorded with a band pass of $0.05-100 \mathrm{~Hz}(0.05-30 \mathrm{~Hz}$ filtered offline) and sampled at a rate of $500 \mathrm{~Hz}$. Each 1000-ms averaging epoch began $100 \mathrm{~ms}$ prior to stimulus onset (allowing for baseline correction). Epochs containing artifacts exceeding $\pm 75 \mu \mathrm{V}$ were rejected. EOG blink artifacts were corrected using a linear regression estimate (Semlitsch, Anderer, Schuster, \& Presslich, 1986). Repeated-measures ANOVAs were employed to analyze the data, including Greenhouse-Geisser corrections when necessary. Bonferroni-correction was applied to post hoc comparisons. The alpha level was 0.05 .

\section{Results}

\subsection{Behavioral results}

The raw proportions of responses for each condition are presented in Table 1. For 
Guess $(G)$ judgements, the proportions of responses to old ( $G$ old) and new (G new) items did not significantly differ $[t(47)=0.54, p=0.592]$. Thus, memory was at chance for these judgements.

Table 1

Mean percentage of responses in test phase for each condition. $S E$ in parentheses.

\begin{tabular}{ccccccccc}
\hline \multirow{2}{*}{$\begin{array}{c}\text { Memory } \\
\text { Judgement }\end{array}$} & \multicolumn{4}{c}{ Studied } & \multicolumn{2}{c}{ Unstudied } & \multicolumn{3}{c}{ Studied } & \multicolumn{3}{c}{ Ulocked } \\
& Primed & Unprimed & Primed & Unprimed & Primed & Unprimed & Primed & Unprimed \\
\hline Remember & $24.5(1.8)$ & $22.2(1.7)$ & $1.3(0.3)$ & $1.5(0.2)$ & $19.8(2.0)$ & $19.6(2.0)$ & $0.9(0.2)$ & $0.2(0.1)$ \\
Know & $25.6(1.8)$ & $28.2(1.7)$ & $9.0(1.3)$ & $9.0(1.1)$ & $28.1(1.4)$ & $26.7(1.4)$ & $6.5(1.0)$ & $5.5(1.2)$ \\
Guess & $19.8(1.2)$ & $19.4(1.2)$ & $20.6(1.7)$ & $19.9(1.5)$ & $24.7(1.6)$ & $25.6(2.2)$ & $23.8(1.9)$ & $23.1(1.7)$ \\
New & $28.7(1.7)$ & $28.9(1.5)$ & $68.6(2.3)$ & $69.0(2.0)$ & $26.3(1.6)$ & $26.4(1.4)$ & $68.2(2.2)$ & $70.6(2.0)$ \\
\hline
\end{tabular}

In order to determine whether masked repetition priming influenced $\mathrm{G}$ judgments, a mixed effects repeated-measures ANOVA employing context $(\mathrm{RC} / \mathrm{BC})$ as a between subjects factor and priming (primed/unprimed) as a nested within subjects factor was performed. For old items (G old), the main effect of context was significant $[F(1,46)=$ $\left.7.038, p=0.011, \eta_{p}{ }_{p}=0.133\right]$, indicating that $\mathrm{G}$ old responses were more likely in the BC than the RC condition (0.251 vs. 0.196), respectively. Neither the main effect of priming $\left[F(1,46)=0.081, p=0.777, \eta_{p}^{2}=0.002\right]$ nor the interaction effect $[F(1,46)=$ $\left.0.466, p=0.498, \eta^{2} p=0.01\right]$ were significant. For new items (G new), no significant effects were revealed (context: $\left[F(1,46)=2.201, p=0.145, \eta_{p}^{2}=0.133\right]$; priming: $\left[F(1,46)=0.434, p=0.513, \eta_{p}^{2}=0.009\right]$; context $\times$ priming interaction: $[F(1,46)<$ $\left.\left.0.001, p=1, \eta_{p}^{2}<0.001\right]\right)$. These results indicate that the proportions of $\mathrm{G}$ judgements were influenced by fluency context but not by the priming manipulation.

Based on the raw proportional data shown in Table 1, we corrected the proportions of $\mathrm{K}$ hit and $\mathrm{K}$ false alarms (applying the formula: corrected $\mathrm{K}=\mathrm{pK} / 1-\mathrm{pR}$ ) according to the independent $\mathrm{R} / \mathrm{K}$ procedure (Yonelinas \& Jacoby, 1995). Subsequent analyses were conducted on raw $\mathrm{R}$ and corrected $\mathrm{K}$ proportions.

In order to examine the influence of masked repetition priming on recollection and familiarity as a function of the context manipulation, a mixed effects ANOVA 
employing context $(\mathrm{RC} / \mathrm{BC})$ as a between subjects factor and response type $(\mathrm{R} / \mathrm{K})$, study status (studied/unstudied), priming (primed/unprimed) as the nested within subjects factor were performed on "old" responses. A significant four-way interaction was obtained $\left[F(1,46)=4.667, p=0.036, \eta^{2} p=0.092\right]$. Therefore, separate mixed effects ANOVAs employing context $(\mathrm{RC} / \mathrm{BC})$ as a between subjects factor and response type $(\mathrm{R} / \mathrm{K})$, priming (primed/unprimed) as the nested within subjects factor were performed on the proportions of hits and false alarms.

For hit rates, the three-way interaction was significant $[F(1,46)=5.201, p=0.027$, $\left.\eta^{2}{ }_{p}=0.102\right]$ in the absence of any other effects. Therefore, two-way ANOVAs employing response type $(\mathrm{R} / \mathrm{K})$ and priming (primed/unprimed) were performed separately for the RC and $\mathrm{BC}$ conditions.

For the RC condition, both the main effect of response type $[F(1,23)=22.557, p$ $\left.<0.001, \eta_{p}^{2}=0.495\right]$ and the response type $\times$ priming interaction were significant $\left[F(1,23)=4.3, p=0.05, \eta_{p}^{2}=0.158\right]$. Follow-up $t$-tests revealed that the priming effect was significant for $\mathrm{R}$ hits $[t(23)=2.212, p=0.037]$, but not for $\mathrm{K}$ hits $[t(23)=-1.409$, $p=0.172]$. ANOVA of the $\mathrm{BC}$ condition revealed only a main effect of response type $\left[F(1,23)=46.365, p<0.001, \eta_{p}^{2}=0.668\right]$, which was indicative of a greater $\mathrm{K}(0.345)$ than $\mathrm{R}(0.197)$ hit rate. Neither the main effect of priming $[F(1,23)=2.292, p=0.144$, $\left.\eta_{p}^{2}=0.091\right]$ nor the priming by response type interaction $[F(1,23)=1.09, p=0.307$, $\left.\eta_{p}^{2}=0.045\right]$ were significant.

Turning to the false alarm rates, the ANOVA revealed main effects of context $\left[F(1,46)=5.756, p=0.021, \eta^{2}{ }_{p}=0.111\right]$ and response type $[F(1,46)=74.053, p<$ $\left.0.001, \eta^{2}{ }_{p}=0.617\right]$. These effects reflected a higher false alarm rate in the RC $(0.052)$ than the $\mathrm{BC}(0.033)$ condition, and more $\mathrm{K}(0.075)$ than $\mathrm{R}(0.01)$ false alarms. No effects involving the factor of priming approached significance (all ps $>0.1$ ). These findings are summarized in Figure 2. 

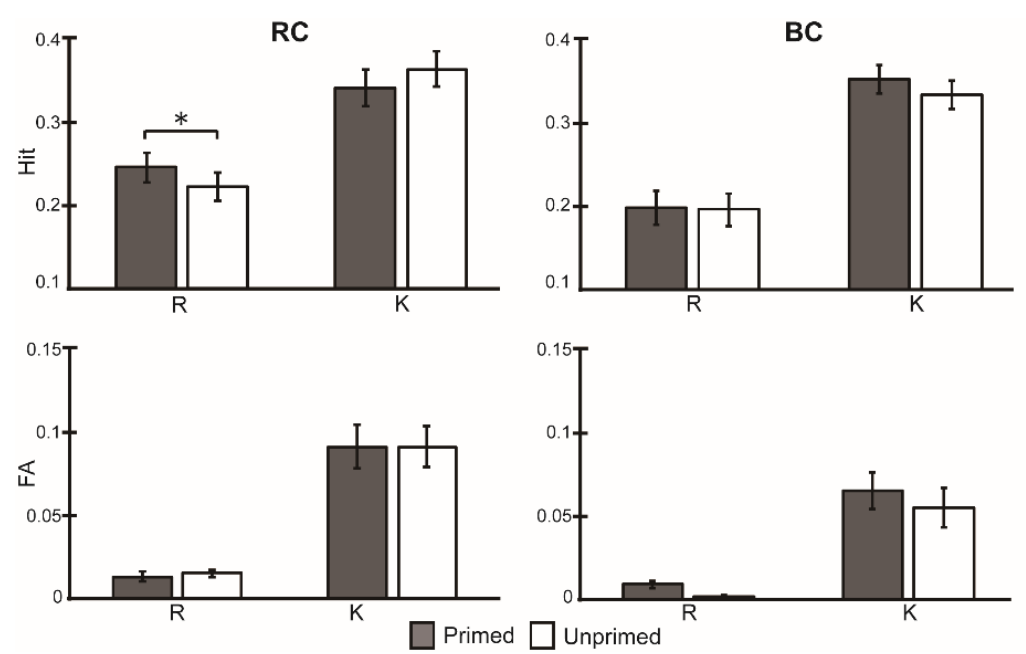

Figure 2. Mean hit rate and false alarm rate of raw $\mathrm{R}$ and corrected $\mathrm{K}$ judgements as a function of priming for $\mathrm{RC}$ and $\mathrm{BC}$ conditions. The error bars indicate standard error. * indicates $p<0.05$.

We also calculated $\mathrm{pR}$ (probability of recollection) and $\mathrm{pF}$ (probability of familiarity-driven recognition) using the formulas: $\mathrm{pR}=\mathrm{R}$ hit $-\mathrm{R}$ false alarms, and $\mathrm{pF}$ $=$ corrected $\mathrm{K}$ hit - corrected $\mathrm{K}$ false alarms. Collapsed across the context and priming conditions, mean $\mathrm{pR}$ and $\mathrm{pF}$ were both reliably greater than zero [for $\mathrm{pR}, M=.27, t(47)$ $=16.69, p<0.001$; for $\mathrm{pF}, M=.27, t(47)=24.917, p<0.001]$. These results indicate that, in contrast to G judgments, memory was above chance levels when participants made either $\mathrm{R}$ or $\mathrm{K}$ judgements.

In order to examine the influence of masked repetition priming on recognition memory accuracy, we calculated $\mathrm{pR}$ and $\mathrm{pF}$ separately for primed and unprimed trials and conducted a mixed effects ANOVA employing context $(\mathrm{RC} / \mathrm{BC})$ as a between subjects factor and response type $(\mathrm{R} / \mathrm{K})$ and priming (primed/unprimed) as nested within subjects factors. The main effect of response type was significant $[F(1,46)=$ 24.017, $\left.p<0.001, \eta^{2}{ }_{p}=0.343\right]$ along with the three-way interaction $[F(1,46)=4.667$, $\left.p=0.036, \eta_{p}^{2}=0.092\right]$. No other main effect or two-way interaction effects were significant (all $p s>0.05$ ). Follow-up two-way ANOVAs employing the factors of response type $(\mathrm{R} / \mathrm{K})$ and priming (primed/unprimed) were performed separately for the $\mathrm{RC}$ and $\mathrm{BC}$ conditions. For the $\mathrm{RC}$ condition, the main effect of response type $[F(1,23)$ $\left.=4.307, p=0.049, \eta_{p}^{2}=0.158\right]$ and the priming $\times$ response type interaction effect $\left[F(1,23)=4.326, p=0.049, \eta^{2}{ }^{2}=0.158\right]$ were both significant. Follow-up $t$-tests 
indicated that the priming effect was significant for $\mathrm{pR},[t(23)=2.448, p=0.022]$, but not for $\mathrm{pF},[t(23)=-1.178, p=0.251]$. For the BC condition, the two-way ANOVA revealed only a significant main effect of response type $[F(1,23)=24.276, p<0.001$, $\left.\eta_{p}^{2}=0.513\right]$. These findings are summarized in Figure 3.
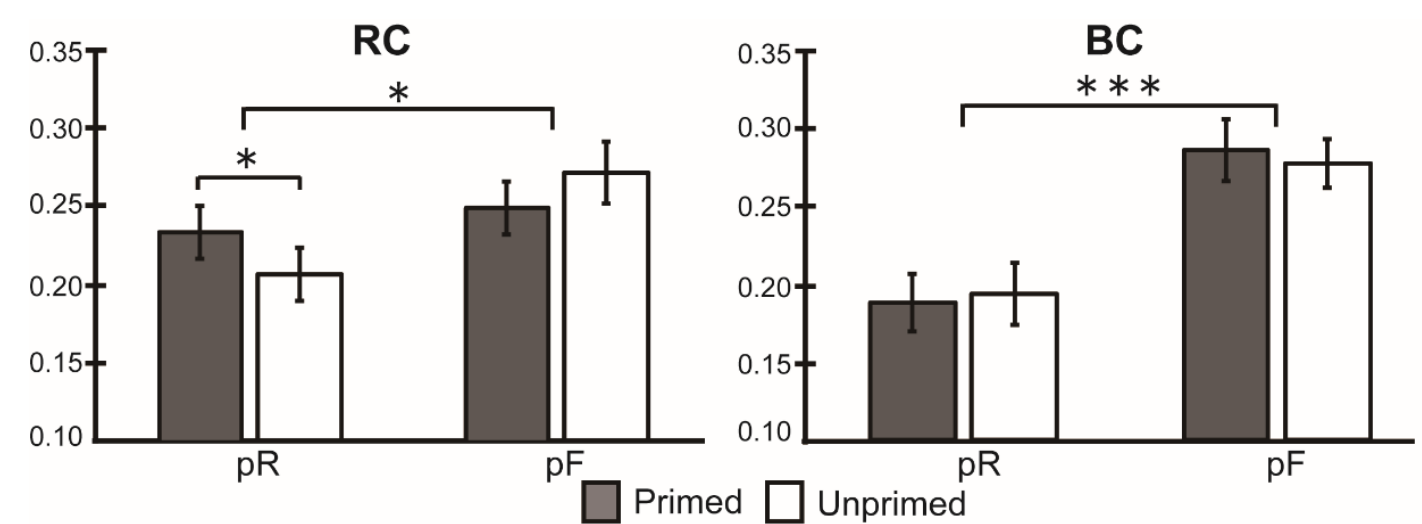

Figure 3. Mean scores for $\mathrm{pR}$ and $\mathrm{pF}$ as a function of priming for $\mathrm{RC}$ and $\mathrm{BC}$ conditions. The error bars indicate standard error. * indicates $p<0.05 . * * *$ indicates $p<0.001$.

In order to examine the effects of masked repetition priming on reaction times (RTs), a mixed effects ANOVA employing context (RC/BC) as a between subjects factor and response category (Hit/CR) and priming (primed/unprimed) as nested within subjects factors was performed (the hit category included only $\mathrm{R}$ and $\mathrm{K}$ hits; $\mathrm{G}$ judgements were excluded). The three-way interaction effect was significant $[F(1,46)$ $\left.=4.202, p=0.046, \eta_{p}^{2}=0.084\right]$. Therefore, follow-up two-way ANOVAs involving category (Hit/CR) and priming (primed/unprimed) were performed separately for the $\mathrm{RC}$ and $\mathrm{BC}$ conditions.

For the RC condition, the main effects of category $[F(1,23)=41.124, p<0.001$, $\eta_{p}^{2}=0.641$ and priming were significant $\left[F(1,23)=6.082, p=0.022, \eta_{p}^{2}=0.209\right]$, as was their interaction $\left[F(1,23)=6.75, p=0.016, \eta_{p}^{2}=0.227\right]$. Follow-up $t$-tests indicated that there was a significant priming effect for Hits $[t(23)=-3.162, p=0.004]$ but not for CRs $[t(23)=0.124, p=0.902]$.

To determine whether the priming effect for hits differed between $\mathrm{R}$ and $\mathrm{K}$ judgments, a two-way ANOVA involving response type ( $\mathrm{R}$ hit/K hit/CR) and priming 
(primed/unprimed) was performed. The main effects of response type $[F(2,46)=$ 38.523, $\left.p<0.001, \eta_{p}^{2}=0.626\right]$ and priming were significant $[F(1,23)=6.745, p=$ $\left.0.016, \eta_{p}^{2}=0.227\right]$, while the interaction effect approached significance $[F(2,46)=$ 3.277, $\left.p=0.053, \eta^{2}{ }^{2}=0.125\right]$. Follow-up $t$-tests indicated that the priming effect was significant for $\mathrm{R}$ hits $[t(23)=-2.883, p=0.008$; primed: $889 \mathrm{~ms}$, unprimed: $921 \mathrm{~ms}$ ], but not for K hits [t(23) $=-1.199, p=0.243$; primed: $967 \mathrm{~ms}$, unprimed: $978 \mathrm{~ms}$ ].

For the BC condition, the two-way ANOVA revealed only a main effect of category $\left[F(1,23)=62.825, p<0.001, \eta^{2}=0.741\right]$, with faster RTs for Hits (1024 ms) than CRs (1252 ms). Neither the main effect of priming $[F(1,23)=1.075, p=0.311$, $\left.\eta_{p}^{2}=0.045\right]$ nor the interaction $\left[F(1,23)=0.745, p=0.397, \eta_{p}^{2}=0.031\right]$ were significant (Figure 4).
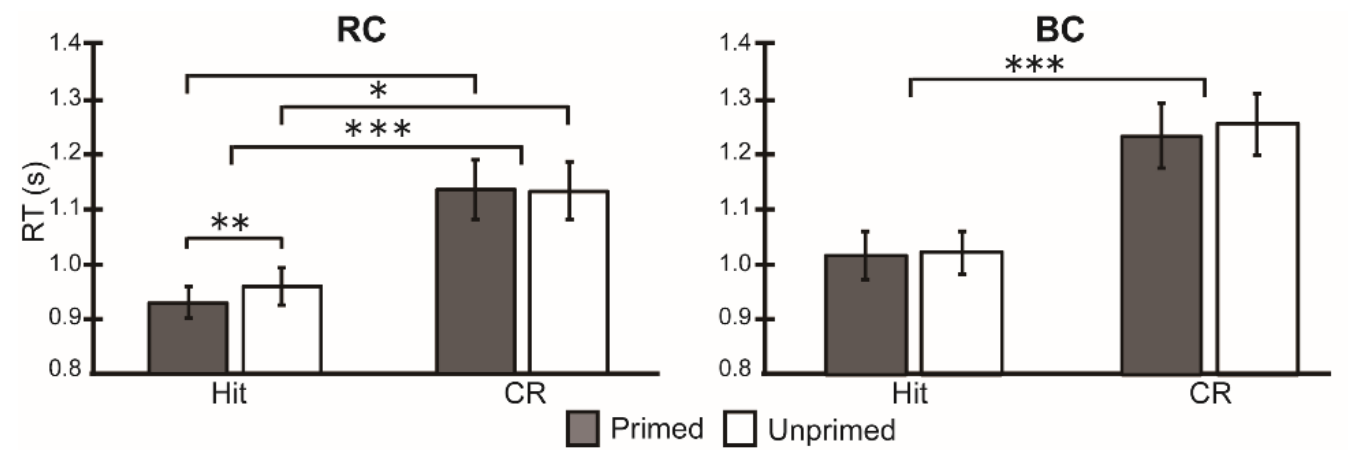

Figure 4. Mean RTs of hit and Correct Rejection as a function of priming for RC and BC conditions. The error bars indicate standard error. ${ }^{*}$ indicates $p<0.05 . * *$ indicates $p<0.01 .{ }^{* * *}$ indicates $p<$ 0.001 .

Overall, as is illustrated in Figures 2-4, masked repetition priming selectively affected $\mathrm{R}$ hit rate and the accuracy of remember judgements in the RC condition. In addition, RTs to R hits were speeded by the priming manipulation in the RC condition but not the $\mathrm{BC}$ condition.

\subsection{ERP results}

Analysis of the ERP results proceeded in two steps. First, ERPs from the test phase were analyzed collapsed across the priming manipulation so to examine ERP 
differences among $\mathrm{R}$ hits, $\mathrm{K}$ hits, $\mathrm{G}$ judgments for old items ( $\mathrm{G}$ old) and Correct Rejections (CRs). Second, to investigate the effects of masked repetition priming, we examined differences between primed and unprimed trials. Based on previous research (Li, et al., 2017; Wang, et al., 2018; Wang, Li, Gao, Xiao, et al., 2015), ERP amplitudes were derived by averaging across three midline electrode clusters. The clusters were frontal: F3, Fz and F4; central: C3, Cz and C4; parietal: P3, Pz and P4.

\subsubsection{Basic memory effects}

A time window of $300 \mathrm{~ms}$ to $500 \mathrm{~ms}$, which is consistent with the time-course of the FN400, and a time window of $500 \mathrm{~ms}$ to $800 \mathrm{~ms}$, which is consistent with the timecourse of the LPC, were employed to index familiarity and recollection effects according to previous studies (e.g., Li, Gao, Wang, \& Guo, 2020; Li, et al., 2017; Rugg, et al., 1998; Woollams, et al., 2008). Grand-average ERP waveforms associated with R hits, $\mathrm{K}$ hits, $\mathrm{G}$ old and CRs, and topographical maps of ERP differences between $\mathrm{R}$ hits and CRs, $\mathrm{K}$ hits and CRs and $\mathrm{R}$ hits and $\mathrm{K}$ hits in the 300-500 ms and 500-800 ms latency intervals are shown in Figure 5. 

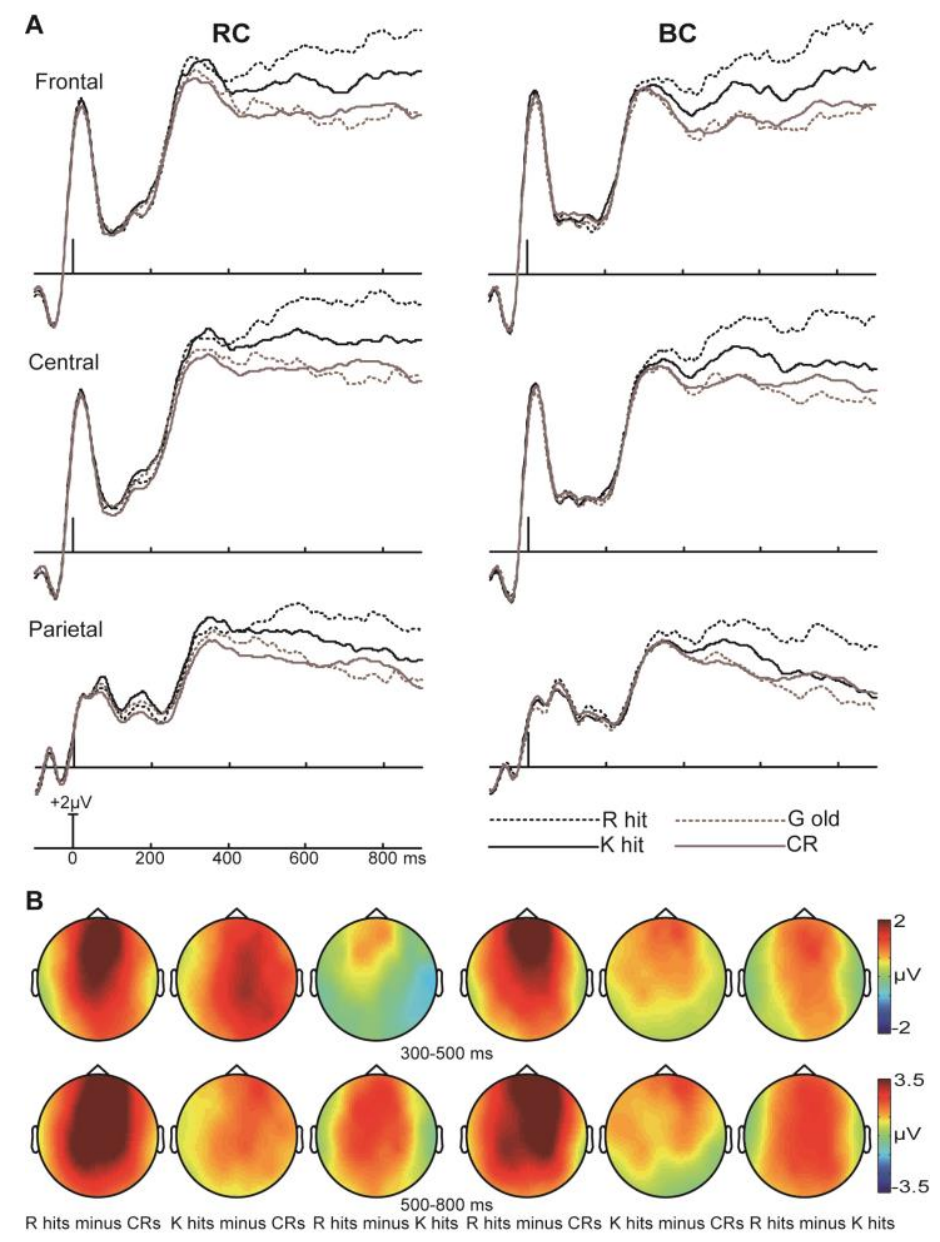

Figure 5. ERPs associated with $\mathrm{R}$ hits, $\mathrm{K}$ hits, $\mathrm{G}$ old and CRs, collapsed across the priming manipulation for $\mathrm{RC}$ and $\mathrm{BC}$ conditions. (A) Waveforms for each condition are shown from frontal electrode to parietal electrode. (B) Topographical plots depicting ERP differences between $\mathrm{R}$ hits and CRs, $\mathrm{K}$ hits and CRs and $\mathrm{R}$ hits and $\mathrm{K}$ hits in the 300-500 ms and 500-800 ms latency intervals.

Two participants in the $\mathrm{RC}$ condition and one participant in $\mathrm{BC}$ condition were removed from the analyses due to fewer than 16 artifact-free trials for one of the response types. For both conditions, the mean numbers of trials contributing to the waveforms for each condition are presented in Table 2. Mixed effects ANOVAs employing context $(\mathrm{RC} / \mathrm{BC})$ as a between subjects factor and response type $(\mathrm{R}$ hit/K hit/G old/CR) and electrode cluster (frontal/central/parietal) as the nested within subjects factors were performed separately for each time window. 
Table 2

Mean numbers of artifact-free epochs for each condition. Range in parentheses.

\begin{tabular}{|c|c|c|c|c|}
\hline & \multicolumn{2}{|c|}{ Random } & \multicolumn{2}{|c|}{ Blocked } \\
\hline & Primed & Unprimed & Primed & Unprimed \\
\hline $\mathrm{R}$ hit & \multicolumn{2}{|c|}{$36(16-56)$} & \multicolumn{2}{|c|}{$31(16-62)$} \\
\hline K hit & \multicolumn{2}{|c|}{$40(23-75)$} & \multicolumn{2}{|c|}{$43(31-76)$} \\
\hline G old & \multicolumn{2}{|c|}{$32(18-49)$} & \multicolumn{2}{|c|}{$41(17-65)$} \\
\hline $\mathrm{CR}$ & \multicolumn{2}{|c|}{$107(78-129)$} & \multicolumn{2}{|c|}{$109(76-138)$} \\
\hline hit & $39(27-56)$ & $39(27-55)$ & $38(26-53)$ & $37(26-57)$ \\
\hline $\mathrm{CR}$ & $54(39-71)$ & $53(38-65)$ & $54(39-70)$ & $56(37-70)$ \\
\hline G & $31(16-48)$ & $30(16-47)$ & $39(24-65)$ & $39(17-66)$ \\
\hline
\end{tabular}

For the 300-500 ms latency interval, the main effect of context was not significant $\left[F(1,43)=0.335, p=0.566, \eta_{p}^{2}=0.008\right]$ but the main effect of response type was significant $\left[F(3,129)=16.815, p<0.001, \eta^{2}{ }_{p}=0.281\right]$. The interaction effect between response type and electrode cluster was significant $\left[F(6,258)=4.309, p=0.005, \eta_{p}{ }_{p}=\right.$ 0.091]. No other two-way or three-way interaction effects were significant ( $p s>0.3)$. Follow-up analyses revealed that the main effect of response type was significant at frontal $\left[F(3,132)=17.624, p<0.001, \eta^{2}=0.286\right]$, central $[F(3,132)=16.712, p<$ $\left.0.001, \eta_{p}^{2}=0.275\right]$ and parietal $\left[F(3,132)=8.623, p<0.001, \eta_{p}^{2}=0.164\right]$ electrode clusters. The results of the post hoc comparisons for these clusters are given in Table 3. As is evident from the table, for the frontal electrode cluster, the amplitude of ERPs elicited by $\mathrm{R}$ hit items was more positive than the ERPs elicited by $\mathrm{K}$ hit, $\mathrm{G}$ old or CR items. In addition, the amplitude of ERPs for $\mathrm{K}$ hits was also more positive than those elicited by G old and CR items, which did not differ from each other. In the cases of the central and parietal electrode clusters, by contrast, the amplitudes of ERPs for R hits did not significantly differ from those for $\mathrm{K}$ hits, but were more positive than those for G old and CR items, which did not differ from each other.

Table 3

Outcomes of the post hoc comparisons for frontal, central and parietal electrode clusters at 300-500 ms time window.

\begin{tabular}{|c|c|c|c|c|c|c|c|c|c|c|c|c|}
\hline & \multicolumn{4}{|c|}{ Frontal } & \multicolumn{4}{|c|}{ Central } & \multicolumn{4}{|c|}{ Parietal } \\
\hline & R hit & K hit & G old & $\mathrm{CR}$ & R hit & K hit & G old & $\mathrm{CR}$ & R hit & K hit & G old & $\mathrm{CR}$ \\
\hline \multicolumn{13}{|l|}{ R hit } \\
\hline K hit & 0.041 & & & & 0.114 & & & & 1.000 & & & \\
\hline
\end{tabular}




$\begin{array}{ccccccccccc}\text { G old } & 0.001 & 0.017 & & 0.001 & 0.036 & & 0.019 & 0.355 & \\ \text { CR } & 0.000 & 0.000 & 1.000 & 0.000 & 0.000 & 1.000 & 0.000 & 0.000 & 1.000\end{array}$

For the 500-800 ms latency interval, the main effect of context was not significant $\left[F(1,43)=0.234, p=0.631, \eta^{2}{ }_{p}=0.005\right]$. As for the earlier interval, both the main effect of response type $\left[F(3,129)=62.996, p<0.001, \eta^{2}{ }_{p}=594\right]$ and its interaction effect between response type and electrode cluster $\left[F(6,258)=6.234, p<0.001, \eta^{2}=0.127\right]$ were significant. No other two-way or three-way interaction effect were significant ( $p s>0.5)$. Follow-up ANOVAs revealed that the main effect of response type was significant at frontal $\left[F(3,132)=52.015, p<0.001, \eta^{2}{ }_{p}=542\right]$, central $[F(3,132)=$ 65.352, $\left.p<0.001, \eta^{2}{ }_{p}=0.598\right]$ and parietal $\left[F(3,132)=45.006, p<0.001, \eta^{2}=0.506\right]$ electrodes clusters. The results of the post hoc comparisons on each cluster are summarized in Table 4. The general pattern across clusters was that $\mathrm{R}$ hit items elicited ERPs that were more positive in this latency range than those for $\mathrm{K}$ hit, G old and CR items, while the ERPs for $\mathrm{K}$ hits were more positive than those for G old and CR items, which did not differ from each other.

\section{Table 4}

Outcomes of the post hoc comparisons for frontal, central and parietal electrode clusters at 500-800 ms time window.

\begin{tabular}{|c|c|c|c|c|c|c|c|c|c|c|c|c|}
\hline & \multicolumn{4}{|c|}{ Frontal } & \multicolumn{4}{|c|}{ Central } & \multicolumn{4}{|c|}{ Parietal } \\
\hline & R hit & K hit & G old & $\mathrm{CR}$ & R hit & K hit & G old & $\mathrm{CR}$ & R hit & K hit & G old & $\mathrm{CR}$ \\
\hline \multicolumn{13}{|l|}{ R hit } \\
\hline $\mathrm{K}$ hit & 0.000 & & & & 0.000 & & & & 0.000 & & & \\
\hline G old & 0.000 & 0.000 & & & 0.000 & 0.000 & & & 0.000 & 0.000 & & \\
\hline $\mathrm{CR}$ & 0.000 & 0.000 & 1.000 & & 0.000 & 0.000 & 0.68 & & 0.000 & 0.004 & 1.000 & \\
\hline
\end{tabular}

For the ERP differences between R hits and CRs in 300-500 ms and 500-800 ms interval, we performed a topographic distributional analysis contrasting the $\mathrm{RC}$ and $\mathrm{BC}$ conditions. The average amplitude differences between $\mathrm{R}$ hit and CR trials were range-normalized following the procedure of McCarthy and Wood (1985). No interaction effects between fluency context and electrode cluster approached significance [for 300-500 ms interval, $F(61,2623)=0.512, p=0.798, \eta^{2}{ }^{2}=0.012$; for 
500-800 ms interval, $\left.F(61,2623)=0.553, p=0.773, \eta^{2} p=0.013\right]$. These results indicated that the $\mathrm{RC}$ and $\mathrm{BC}$ conditions had similar topographical distribution for $\mathrm{R}$ hit minus CR contrasts. Similarly, in the topographical analyses conducted on the ERP differences between $\mathrm{K}$ hits and $\mathrm{CRs}$ for the $\mathrm{RC}$ and $\mathrm{BC}$ conditions, we did not identify significant fluency context $\times$ electrode cluster interaction in either the 300$500 \mathrm{~ms}$ or the 500-800 ms interval [for 300-500 ms interval, $F(61,2623)=0.846, p=$ $0.533, \eta^{2}=0.019$; for 500-800 ms interval, $F(61,2623)=1.625, p=0.138, \eta^{2} p=$ 0.036]. Thus, the topographical distribution for $\mathrm{K}$ hit minus CR contrasts did not differ across the conditions.

\subsection{2. masked repetition priming effect}

In order to investigate the effects of masked repetition priming, we contrasted priming effects for hits and CRs in the $\mathrm{RC}$ and $\mathrm{BC}$ conditions. Because of the low trial numbers when hits were separated according to whether they were endorsed as R or K, we combined the two judgments for these analyses. Mean amplitudes between 100-200 $\mathrm{ms}, 300-500 \mathrm{~ms}$ and 500-800 ms were employed as the dependent variables for these analyses based on previous studies (Li, et al., 2017; Wang, et al., 2018). The mean numbers of artifact-free epochs for each condition are presented in Table 2. A mixed effects repeated-measures ANOVA employing context $(\mathrm{RC} / \mathrm{BC})$ as a between subjects factor and response type (hit/CR), priming (primed/unprimed) and electrode cluster (frontal/central/parietal) as the within subjects factors was performed separately for each time interval.

For the 100-200 ms interval, the main effect of context was not significant $[F(1,46)$ $\left.=0.275, p=0.602, \eta_{p}^{2}=0.006\right]$, and nor was the effect of response type $[F(1,46)=$ $\left.0.189, p=0.666, \eta^{2}{ }^{2}=0.004\right]$. The main effect of priming was significant however $\left[F(1,46)=32.54, p<0.001, \eta^{2}{ }^{2}=0.414\right]$, reflecting the fact that the amplitude of ERPs elicited by primed items was more positive than the ERPs elicited by unprimed items. The interaction effect between priming and electrode cluster was also significant $\left[F(2,92)=122.443, p<0.001, \eta^{2}{ }_{p}=0.727\right]$. Follow-up $t$-tests revealed that the effect of priming was significant at frontal $[t(47)=8.541, p<0.001]$ and central $[t(47)=$ 
7.225, $p<0.001]$ electrode clusters, but not at parietal cluster $[t(47)=-0.668, p=$ 0.507]. No other interaction effects involving the priming factor were significant ( $p s>$ $0.5)$.

For the $300-500 \mathrm{~ms}$ interval, the main effect of context was not significant $[F(1,46)$ $\left.=0.532, p=0.47, \eta_{p}^{2}=0.011\right]$, while the main effects of response type $[F(1,46)=$ 55.929, $\left.p<0.001, \eta^{2}{ }_{p}=0.549\right]$ and priming $\left[F(1,46)=7.325, p=0.01, \eta^{2}{ }_{p}=0.137\right]$ both attained significance. The results reflected the facts that ERPs elicited by hits were more positive than those elicited by CRs, and that the ERPs elicited by primed items were more positive than those elicited by unprimed items. No other two-way, threeway or four-way interaction effects involving priming were significant ( $p s>0.09$ ).

For the 500-800 ms interval, neither the main effects of context $[F(1,46)=0.551$, $\left.p=0.462, \eta_{p}^{2}=0.012\right]$ or priming $\left[F(1,46)=0.721, p=0.4, \eta_{p}^{2}=0.015\right]$ was significant, while the main effect of response type was significant $[F(1,46)=68.932, p$ $\left.<0.001, \eta_{p}^{2}=0.6\right]$. Among the interaction effects, only the four-way interaction was significant $\left[F(2,92)=3.468, p=0.045, \eta_{p}^{2}=0.07\right]$. The interaction was followed up with two-way ANOVAs employing priming (primed/unprimed) and electrode cluster (frontal/central/parietal) performed separately in the RC and $\mathrm{BC}$ conditions for each response type. For the RC condition, the ANOVA revealed a marginal interaction effect between priming and electrode cluster for hits $\left[F(2,46)=3.508, p=0.052, \eta^{2}{ }_{p}=0.132\right]$. Follow-up $t$-tests failed to reveal a priming effect in any electrode clusters $(p s>0.2)$. For the $\mathrm{BC}$ condition, no effects were significant (all $p s>0.1$ ).

In summary, as is shown in Figure 6, the masked repetition priming effect evident during the 100-200 ms and 300-500 ms intervals, which took the form of greater positivity for primed than unprimed trials, was closely similar in the RC and BC conditions and for the different response types. 

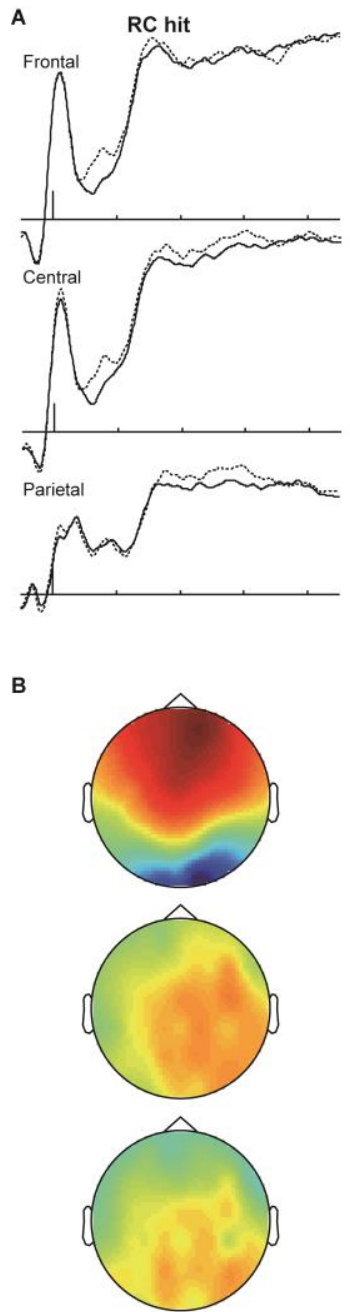
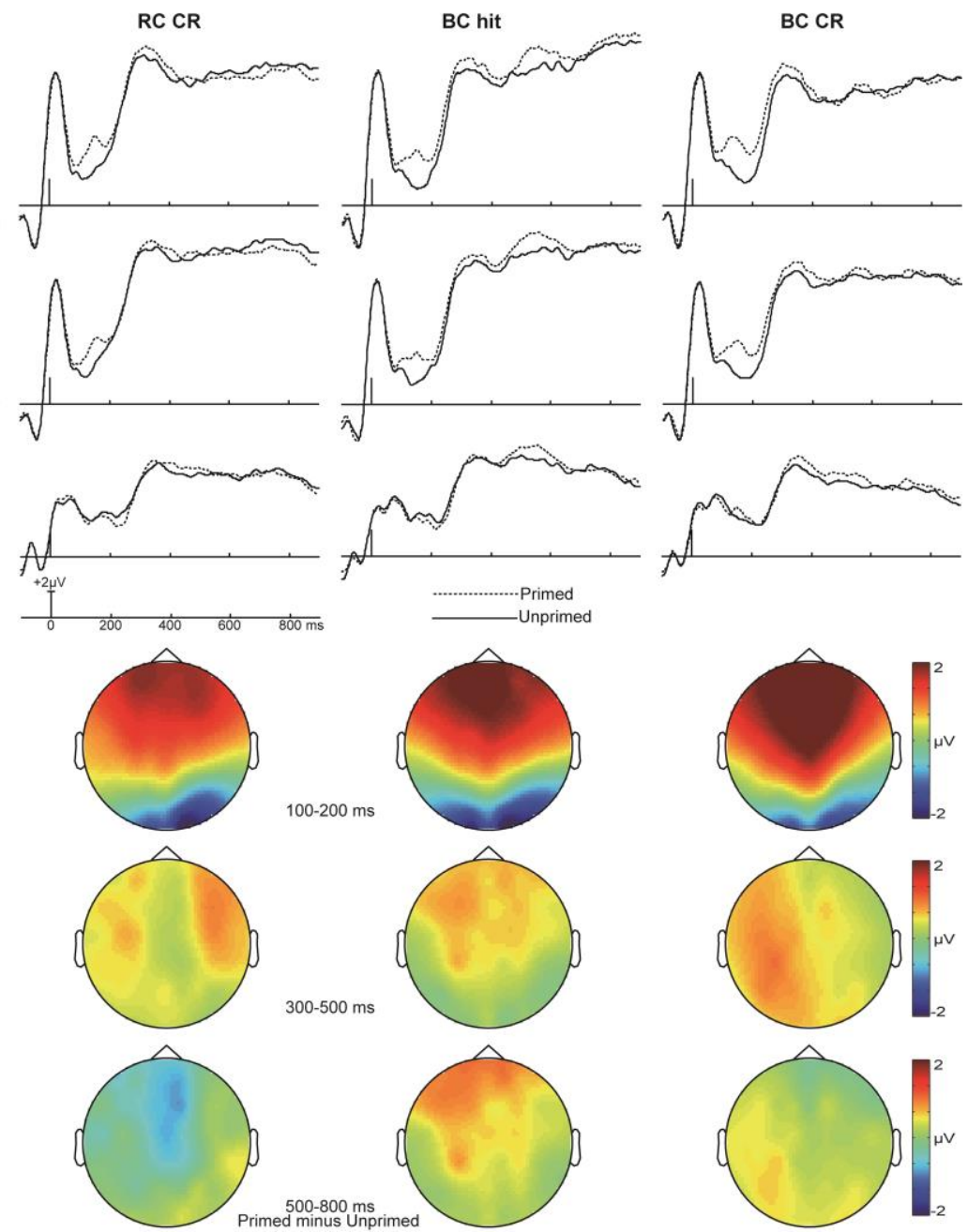

Figure 6. Masked repetition priming effects for hits and $\mathrm{CRs}$ in the $\mathrm{RC}$ and $\mathrm{BC}$ conditions. (A) Grand averaged waveforms of primed and unprimed trials under hit and CR conditions are shown for each electrode chain. (B) Topographic plots depict ERP differences between primed and unprimed trials at $100-200 \mathrm{~ms}, 300-500 \mathrm{~ms}$ and $500-800 \mathrm{~ms}$ for hit and CR.

We also examined priming effects in the 100-200 ms interval for Guess (G) judgements. Because of low trial numbers for the Guess old and new items in each priming condition, we combined the two trial types. One participant in the $\mathrm{BC}$ condition was removed due to fewer than 16 artifact-free trials for the $\mathrm{G}$ primed condition. The mean numbers of artifact-free epochs for the $\mathrm{G}$ primed and $\mathrm{G}$ unprimed conditions are given in Table 2. A mixed effects repeated-measures ANOVA employing context $(\mathrm{RC} / \mathrm{BC})$ as a between subjects factor and priming ( $\mathrm{G}$ primed/G unprimed), electrode cluster (frontal/central/parietal) as the within subjects factors was performed for 100- 
$200 \mathrm{~ms}$ interval.

The ANOVA revealed a non-significant effect of context $[F(1,45)=0.311, p=$ $\left.0.58, \eta^{2} p=0.007\right]$, along with a significant effect of priming $[F(1,45)=14.323, p<$ $\left.0.001, \eta^{2}{ }^{2}=0.241\right]$ and a significant interaction between priming and electrode cluster $\left[F(2,90)=38.785, p<0.001, \eta_{p}^{2}=0.463\right]$. Follow-up $t$-tests revealed that the effect of priming was significant for the frontal $[t(46)=5.842, p<0.001]$ and central $[t(46)=$ 4.581, $p<0.001]$ electrode clusters, but not for the parietal $[t(46)=0.101, p=0.92]$ cluster. In short, as is illustrated in Figure 7, ERPs elicited on G trials demonstrated a very similar priming effect during the 100-200 ms interval to the effects observed for hits and CRs.

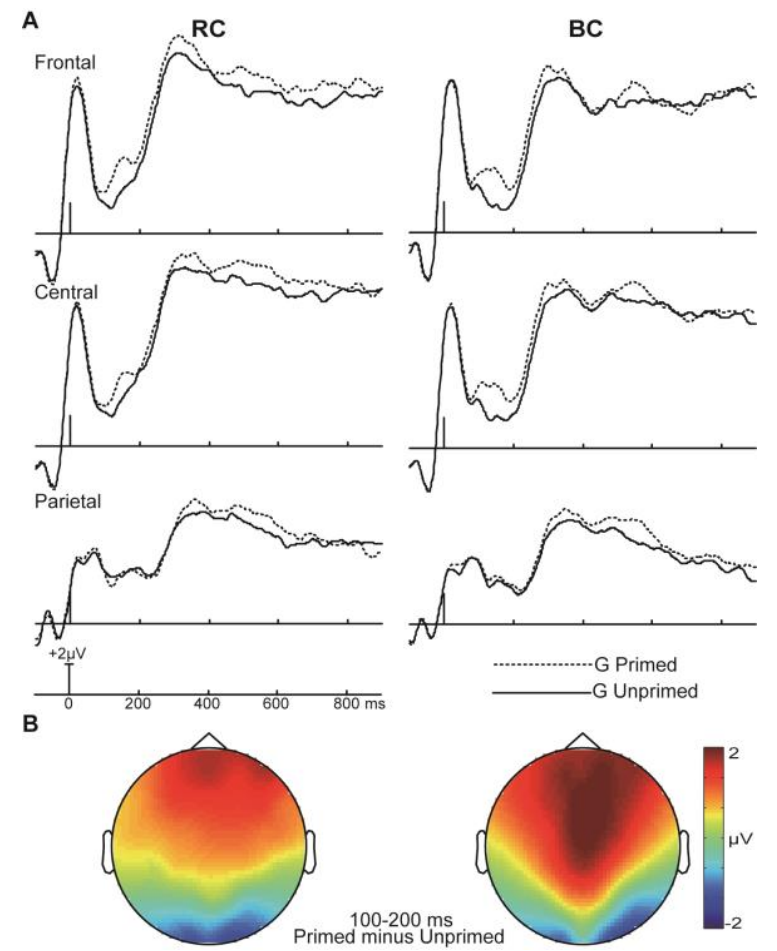

Figure 7. Masked repetition priming effects for $\mathrm{G}$ responses in the $\mathrm{RC}$ and $\mathrm{BC}$ conditions. (A) Grand average waveforms of primed and unprimed trials for $G$ responses for each electrode chain. (B) Topographic plots depicting the difference between primed and unprimed trials for the $100-200 \mathrm{~ms}$ latency interval in each context condition.

Although we observed a behavioral priming effect on $\mathrm{R}$ judgements only for the $\mathrm{RC}$ condition, the early ERP priming effect did not differ according to response type or 
fluency context. To further examine whether the effect was selectively sensitive to $\mathrm{R}$ hits in the RC condition (and hence paralleled the behavioral findings), we conducted a mixed effects repeated-measures ANOVA on the ERPs elicited by $\mathrm{R}$ hits. The ANOVA was restricted to data from those participants with at least 12 trials in each critical condition ( $\mathrm{n}=16$ and $\mathrm{n}=12$ for the $\mathrm{RC}$ and $\mathrm{BC}$ conditions respectively).

For the 100-200 ms interval, the main effect of context was not significant $[F(1,26)$ $\left.=0.012, p=0.912, \eta_{p}^{2}<0.001\right]$. The main effect of priming was significant $[F(1,26)=$ 4.7, $p=0.04, \eta_{p}^{2}=0.153$ ], but this was modified by a significant interaction between priming and electrode cluster $\left[F(2,52)=30.983, p<0.001, \eta^{2} p=0.544\right]$. Follow-up $t$ tests revealed that the effect of priming was significant at frontal $[t(27)=3.37, p=$ $0.002]$ and central $[t(27)=2.83, p=0.009]$ electrode clusters, but not at the parietal $[t(27)=-0.184, p=0.855]$ cluster. No other two-way or three-way interaction effect involving priming were significant ( $p s>0.8$ ). Thus, these findings exactly parallel those obtained for the ERPs collapsed across the two classes of memory judgments. For the 300-500 ms interval, the main effect of context was again non-significant $\left[F(1,26)=0.402, p=0.531, \eta^{2} p=0.015\right]$, as was the priming effect $[F(1,26)=1.525, p$ $\left.=0.228, \eta_{p}^{2}=0.055\right]$. No interaction effects involving priming were significant $(p s>$ $0.3)$. These findings were paralleled in the case of the 500-800 ms interval. Neither the main effects [context: $F(1,26)=0.911, p=0.349, \eta^{2}{ }_{p}=0.034$; priming $F(1,26)=0.353$, $\left.p=0.557, \eta^{2}{ }_{p}=0.013\right]$ nor any interaction effects were significant $(p s>0.4)$.

\section{Discussion}

The purpose of present study was to investigate the contribution of perceptual fluency to recognition memory in different 'fluency contexts'. We manipulated the perceptual fluency of recognition test cues through masked repetition priming and examined the fluency effect in random (RC) and blocked context (BC) conditions. Behavioral results showed that masked repetition priming affected the incidence of $\mathrm{R}$ hits and the accuracy of R judgements in the RC condition, while these effects were not evident in the $\mathrm{BC}$ condition. In addition, the effects of masked repetition priming on $\mathrm{RT}$ were found only for $\mathrm{R}$ hit responses in the RC condition. The ERP results revealed 
an early 100-200 ms ERP correlate of masked repetition priming. In striking contrast to the aforementioned behavioral measures, this effect was modulated neither by fluency context or response type. In the following, we discuss our findings in detail.

\subsection{Masked repetition priming effect on recognition memory in $\mathrm{RC}$ and $\mathrm{BC}$ conditions}

The behavioral data indicated that masked repetition priming selectively affected $\mathrm{R}$ hit rate and accuracy of $\mathrm{R}$ judgements in the $\mathrm{RC}$ condition. On the assumption that priming exerted its effect by modulating perceptual fluency, the finding that priming only impacted on recognition memory judgments in the RC condition is consistent with previous studies (Gomes, et al., 2017; Leynes \& Zish, 2012). As Leynes and Zish (2012) proposed, the RC condition, in which fluency varied randomly across trials, likely leads to a situation in which repetition fluency (due to exposure in the study phase) and perceptual fluency (from masked repetition priming) interact. In the present study, this dynamic interaction between the two sources of fluency affected recognition judgments, particularly $\mathrm{R}$ judgments. In addition, RTs for $\mathrm{R}$ hits were faster in the primed than in the unprimed condition.

Previous studies reported that fluency induced by masked repetition priming affected familiarity but not recollection (e.g., Lucas, et al., 2012; Woollams, et al., 2008). However, there are some studies suggesting that fluency may also affect recollection. For example, Taylor and his colleagues employed both conceptual and repetition primes in a recognition memory test and found that conceptual primes increased the proportion of R judgements to studied items (Taylor, et al., 2013; Taylor \& Henson, 2012). In addition, studies conducted in our laboratory also suggest that masked conceptual priming can increase the incidence of R judgements ( $\mathrm{Li}$, et al., 2017; Wang, et al., 2018; Wang, Li, Gao, Xu, et al., 2015). In a recent ERP study, Park and Donaldson (2016) used masked repetition priming paradigm in a recognition memory test. They found that response times to studied items were faster in the primed condition and that the onset of the left-parietal old/new effect, which is associated with recollection, was earlier for primed trials. Therefore, they speculated that masked 
repetition priming speeds recollection. In an fMRI study, Gomes, et al. (2017) employed low frequency words as stimuli and found that the influence of masked repetition priming on recognition memory was restricted to high confidence responses.

The $\mathrm{R} / \mathrm{K}$ paradigm has been widely used to segregate recognition judgments based on recollection and familiarity (for review see Migo, Mayes, \& Montaldi, 2012). However, single process theories propose that $\mathrm{R}$ and $\mathrm{K}$ judgments are simply reflections of different degrees of memory strength (Donaldson, 1996; Dunn, 2004, 2008). Therefore, there is a possibility that the $\mathrm{R}$ and $\mathrm{K}$ judgements in present experiment merely reflect high and low confidence responding respectively, and variations in relative fluency in the $\mathrm{RC}$ condition led participants to adopt a more liberal response criterion when making $\mathrm{R}$ responses. Although we instructed participants that $\mathrm{R} / \mathrm{K}$ responses should not be treated as confidence ratings and, indeed, instructed them to report the reasons behind their responses in practice trials, it is not possible to know whether participants adhered to the instructions consistently during the rest of the experiment. Of relevance, in the RC condition, the discriminability (d') indices for R judgements and for overall item memory ( $\mathrm{R}$ plus $\mathrm{K}$ judgements) did not differ significantly [respectively: $d^{\prime}=1.366$ and $1.336, t(23)=0.517, p=0.61$ ], as is predicted by single process theories (Donaldson, 1996). In addition, d' for item memory did not significantly differ between the primed and unprimed conditions [RC condition, primed: $d^{\prime}=1.375$, unprimed: $\left.d^{\prime}=1.326, t(23)=0.656, p=0.518\right]$, implying that priming did not impact memory strength. However, when we calculated a response bias index $(\mathrm{Br})$ for $\mathrm{R}$ responses in the primed and unprimed conditions, no significant difference in $\mathrm{Br}$ estimates was detected $[t(23)=-0.773, p=0.447$; primed: 0.017, unprimed: 0.019]. We think it possible that these null findings for $\mathrm{R} \mathrm{d}$ ' and $\mathrm{Br}$ might be a consequence of the near-floor false alarm rates for $\mathrm{R}$ judgments (see Table 1), which may have obscured an influence of fluency on R false alarms.

In order to investigate the possibility that fluency impacted "guess" responses (cf., Tunney \& Fernie, 2007), we added a "guess" option to our R/K procedure. The behavioral results indicated that accuracy of guess responses was at chance level and was uninfluenced by the perceptual fluency manipulation. In addition, we compared 
ERPs elicited by guess and CR trials and found no differences between these response types in either the $300-500 \mathrm{~ms}$ or $500-800 \mathrm{~ms}$ time windows. Therefore, the present results suggest that above-chance accuracy of guess responses reported by Voss and Paller (2009a) might occur only in forced-choice tests. We were unable to identify any effects of perceptual fluency in FAs in either fluency context. By contrast, Gomes, Mecklinger, and Zimmer (2019) reported a behavioral priming effect for low confidence (LC) false alarms (FAs) in both RC and BC conditions, with more FAs in the primed than the unprimed condition. This divergence between the present and prior findings might reflect the different encoding tasks used in the two studies. Because the stimuli in present study were meaningless and highly similar to each other we employed an intentional encoding task so as to obtain acceptable rates of recognition accuracy. By contrast, Gomes, et al. (2019) employed an incidental 'shallow' encoding task to prompt the use of fluency at later test. Had we used a shallow incidental encoding task, it is possible that we might have found a priming effect on guess responses.

Taken together, our behavioral findings suggest that the manipulation of fluency context can moderate the effects of perceptual fluency on recognition memory. Clearly, the processes by which item fluency is attributed in such way as to influence recognition memory judgements are complex and likely are influenced by many factors. Future research is needed to explore whether the effects of context identified in the present study extend to other types of fluency, such as conceptual fluency.

\subsection{Electrophysiological correlates of basic memory effects}

Two classic ERP components, the FN400 effect, which is associated with familiarity, and the LPC effect, which is associated with recollection (for review, see Rugg \& Curran, 2007), were the focus of the present study. We were however unable to identify either effect in the present data. Instead, we identified topographically diffuse old/new effects in both the $300-500 \mathrm{~ms}$ and $500-800 \mathrm{~ms}$ latency ranges. That is, ERPs elicited by $\mathrm{R}$ and $\mathrm{K}$ hits were more positive than those elicited by CRs in the two latency intervals. These effects did not significantly differ between the RC and BC conditions. Furthermore, as previously mentioned, the ERPs elicited by guess responses 
did not differ from those elicited by CRs, and were significantly more negative-going than the ERPs for $\mathrm{R}$ and $\mathrm{K}$ hits. These results converge with the behavioral data to suggest that guess responses were not associated with a functionally relevant memory signal.

\subsection{Electrophysiological correlates of masked repetition priming}

We identified an early (100-200 ms) fronto-centrally distributed ERP correlate of masked repetition priming, which took the form of greater positivity for primed than unprimed trials. This effect was not modulated by fluency context and did not vary with response type. A similar early effect was identified in previous studies conducted in our lab (Li, et al., 2017; Wang, et al., 2018; Wang, Li, Gao, Xiao, et al., 2015). Wang, et al. (2018) employed the same method as Leynes and Zish (2012) to manipulate perceptual fluency (manipulating the clarity of the test items) and reported that fluent items elicited more positive ERPs than less fluent items between 100 and 200 ms post-stimulus. Li, et al. (2017) employed both masked repetition and conceptual priming manipulations in a recognition memory test. An early frontally-centrally distributed ERP effect (100$200 \mathrm{~ms}$ ) was observed only for the repetition priming manipulation, such that the ERPs elicited by primed trials were more positive than those of unprimed trials. More importantly, when we used stimuli with varying levels of meaningfulness (Wang, Li, Gao, Xiao, et al., 2015), masked repetition priming of low meaningfulness items gave rise to an ERP effect between 150-250 ms post-stimulus. Other researchers, for example, Woollams, et al. (2008), have also reported a masked repetition priming effect with a roughly similar time-course (150-250 ms) and an anterior distribution. We hypothesize that this early ERP effect might be associated with elevated perceptual fluency induced by masked repetition priming, and reflect facilitation of perceptual processing.

In contrast to the findings of the present study and the studies mentioned above, other studies that have investigated ERP correlates of the manipulation of perceptual fluency reported that enhanced fluency was associated with more negative-going early ERP deflections (Leynes \& Zish, 2012; Rugg, Soardi, \& Doyle, 1995; Voss \& Paller, 
2010). One explanation for these discrepant results, according to Voss and Paller (2010), is that the direction of ERP masked repetition effects might depend on the nature of the memory task (i.e., direct vs. indirect). Positive repetition effects might be found during direct memory tests that arguably depend heavily on explicit memory, while negative repetition effects might emerge in indirect tests where performance is more strongly influenced by implicit memory. However, irrespective of the nature of memory tests, the experimental settings in the studies that have investigated the effects of perceptual fluency on ERPs differ in numerous ways (e.g., the nature of the study task, the meaningfulness of experimental items, the means by which fluency was manipulated), and these different factors, either jointly or individually, might also play a role in explaining the disparate polarities of the effects of fluency on ERPs (see also Leynes and Zish, 2012).

In striking contrast to our ERP findings, a behavioral effect of masked priming was evident only in the RC condition and was restricted to R judgements. Given that the present early ERP effect occurred in both fluency contexts and across all of the different response types, the effect seems to reflect enhanced perceptual fluency independently of whether this influenced recognition memory judgements. In other words, enhanced fluency may have been necessary, but was not sufficient, for fluency to exert an influence on recognition judgements. Indeed, numerous findings suggest that enhanced fluency is not automatically attributed to past experience, and that the employment of fluency as a heuristic during recognition decisions requires additional processing before such an attribution is made (Jacoby \& Whitehouse, 1989; Kleider \& Goldinger, 2004; Westerman, et al., 2002; Whittlesea, et al., 1990). Thus, the neural activity related to attributional processing might be dissociable from that related to fluency itself (Kurilla \& Gonsalves, 2012; Lucas \& Paller, 2013; Wolk, et al., 2004). For example, Kurilla and Gonsalves (2012) manipulated whether participants were or were not encouraged to attribute enhanced perceptual fluency to prior study. The authors reported a mid-latency (300-500 ms) posteriorly distributed ERP effect that was evident regardless of task condition, and a later (500-700 ms) frontally distributed ERP effect that was most pronounced in participants who were reluctant to attribute 
enhanced fluency to prior experience. Given that the present study was not designed to separate the neural correlates of fluency and attributional processes, no firm conclusions of this issue can be drawn on the basis of the data reported here.

In addition to the early effect, we also identified a later ERP masked repetition priming effect in the $300-500 \mathrm{~ms}$ latency region (Figure 6). The effect overlaps the latency of the typical N400 component and was independent of fluency context and response type. Several previous studies that investigated the relationship between masked repetition priming and recognition memory observed modulation of an N400 component and associated this with the effects of fluency on recognition memory $(\mathrm{Li}$, et al., 2017; Lucas, et al., 2012; Woollams, et al., 2008). These studies most typically employed meaningful words as stimuli. The present 300-500 ms effect was an unexpected result given our employment of meaningless stimuli. The N400 component that occupies this latency range is sensitive to lexical and semantic processing (Kutas \& Hillyard, 1980; Petten, Kutas, Kluender, Mitchiner, \& McIsaac, 1991). We do not suggest that the 300-500 ms effect identified in the present study reflects the modulation of the N400. Rather, it might simply reflect the continuation of the early effect identified in the $100-200 \mathrm{~ms}$ latency window.

In summary, we provide new evidence that perceptual fluency induced by masked repetition priming affects recollection-related memory judgments in a specific fluency context. The neural correlates of perceptual fluency, by contrast, appear to be insensitive to fluency context. Thus, the present findings suggest that it is relative rather absolute fluency that plays a critical role in influencing recognition memory judgments. The present findings thereby extend our knowledge about the interaction between implicit memory and recognition memory.

\section{Acknowledgments}

The present study was supported by Fundamental Research Funds for the Central Universities to Wei Wang (GK201703072), National Natural Science Foundation of China (31700976) to Yadan Li and National Natural Science Foundation of China (31700954) to Bingbing Li. We thank Jing Liu and Weishan Tong for their assistance 
of data collection. We thank Dr. Chunyan Guo at Beijing Key Laboratory of Learning and Cognition for his helpful suggestions during study design.

\section{References}

Bridger, E. K., Bader, R., Kriukova, O., Unger, K., \& Mecklinger, A. (2012). The FN400 is functionally distinct from the N400. Neuroimage, 63, 1334-1342.

Bridger, E. K., Bader, R., \& Mecklinger, A. (2014). More ways than one: ERPs reveal multiple familiarity signals in the word frequency mirror effect. Neuropsychologia, 57, 179190.

Bruett, H., \& Leynes, P. A. (2015). Event-related potentials indicate that fluency can be interpreted as familiarity. Neuropsychologia, 78, 41-50.

Curran, T. (2000). Brain potentials of recollection and familiarity. Memory \& Cognition, 28, 923-938.

Curran, T., \& Cleary, A. M. (2003). Using ERPs to dissociate recollection from familiarity in picture recognition. Cognitive Brain Research, 15, 191-205.

Donaldson, W. (1996). The role of decision processes in remembering and knowing. Memory \& Cognition, 24, 523-533.

Dunn, J. C. (2004). Remember-know: a matter of confidence. Psychological review, 111, 524542.

Dunn, J. C. (2008). The dimensionality of the remember-know task: a state-trace analysis. Psychological review, 115, 426-446.

Gao, C., Hermiller, M. S., Voss, J. L., \& Guo, C. (2015). Basic perceptual changes that alter meaning and neural correlates of recognition memory. Frontiers in Human Neuroscience, 9, 1-10.

Gomes, C. A., Mecklinger, A., \& Zimmer, H. (2017). Behavioural and neural evidence for the impact of fluency context on conscious memory. Cortex, 92, 271-288.

Gomes, C. A., Mecklinger, A., \& Zimmer, H. (2019). The neural mechanism of fluency-based memory illusions: the role of fluency context. Learn Mem, 26, 61-65.

Hou, M., Safron, A., Paller, K. A., \& Guo, C. (2013). Neural correlates of familiarity and conceptual fluency in a recognition test with ancient pictographic characters. Brain Res, 1518, 48-60.

Jacoby, L. L., \& Whitehouse, K. (1989). An illusion of memory: False recognition influenced by unconscious perception. Journal of Experimental Psychology: General, 118, 126135.

Johnston, W. A., Hawley, K. J., \& Elliott, J. M. (1991). Contribution of perceptual fluency to recognition judgments. Journal of Experimental Psychology: Learning, Memory, and Cognition, 17, 210.

Kleider, H. M., \& Goldinger, S. D. (2004). Illusions of face memory: Clarity breeds familiarity. J Mem Lang, 50, 196-211.

Kurilla, B. P., \& Gonsalves, B. D. (2012). An ERP investigation into the strategic regulation of the fluency heuristic during recognition memory. Brain Res, 1442, 36-46. 
Kutas, M., \& Hillyard, S. A. (1980). Reading senseless sentences: Brain potentials reflect semantic incongruity. Science, 207, 203-205.

Leynes, P. A., \& Addante, R. J. (2016). Neurophysiological evidence that perceptions of fluency produce mere exposure effects. Cognitive, Affective, \& Behavioral Neuroscience, 16, 754-767.

Leynes, P. A., \& Zish, K. (2012). Event-related potential (ERP) evidence for fluency-based recognition memory. Neuropsychologia, 50, 3240-3249.

Li, B., Gao, C., Wang, W., \& Guo, C. (2020). The effect of conceptual priming on subsequent familiarity: Behavioral and electrophysiological evidence. Biological Psychology, 149, 107783.

Li, B., Taylor, J. R., Wang, W., Gao, C., \& Guo, C. (2017). Electrophysiological signals associated with fluency of different levels of processing reveal multiple contributions to recognition memory. Consciousness and cognition, 53, 1-13.

Lucas, H. D., \& Paller, K. A. (2013). Manipulating letter fluency for words alters electrophysiological correlates of recognition memory. Neuroimage, 83, 849-861.

Lucas, H. D., Taylor, J. R., Henson, R. N., \& Paller, K. A. (2012). Many roads lead to recognition: electrophysiological correlates of familiarity derived from short-term masked repetition priming. Neuropsychologia, 50, 3041-3052.

McCarthy, G., \& Wood, C. C. (1985). Scalp distributions of event-related potentials: an ambiguity associated with analysis of variance models. Electroencephalography and Clinical Neurophysiology, 62, 203-208.

Migo, E. M., Mayes, A. R., \& Montaldi, D. (2012). Measuring recollection and familiarity: Improving the remember/know procedure. Consciousness and cognition, 21, 14351455.

Oppenheimer, D. M. (2008). The secret life of fluency. Trends Cogn Sci, 12, 237-241.

Paller, K. A., Voss, J. L., \& Boehm, S. G. (2007). Validating neural correlates of familiarity. Trends Cogn Sci, 11, 243-250.

Park, J. L., \& Donaldson, D. I. (2016). Investigating the relationship between implicit and explicit memory: Evidence that masked repetition priming speeds the onset of recollection. Neuroimage, 139, 8-16.

Petten, C. V., Kutas, M., Kluender, R., Mitchiner, M., \& McIsaac, H. (1991). Fractionating the word repetition effect with event-related potentials. Journal of Cognitive Neuroscience, 3, 131-150.

Rajaram, S. (1993). Remembering and knowing: Two means of access to the personal past. Memory \& Cognition, 21, 89-102.

Rajaram, S., \& Geraci, L. (2000). Conceptual fluency selectively influences knowing. Journal of Experimental Psychology: Learning, Memory, and Cognition, 26, 1070-1074.

Rugg, M. D., \& Curran, T. (2007). Event-related potentials and recognition memory. Trends Cogn Sci, 11, 251-257.

Rugg, M. D., Mark, R. E., Walla, P., Schloerscheidt, A. M., Birch, C. S., \& Allan, K. (1998). Dissociation of the neural correlates of implicit and explicit memory. Nature, 392, 595598.

Rugg, M. D., Soardi, M., \& Doyle, M. C. (1995). Modulation of event-related potentials by the repetition of drawings of novel objects. Cognitive Brain Research, 3, 17-24. 
Semlitsch, H. V., Anderer, P., Schuster, P., \& Presslich, O. (1986). A solution for reliable and valid reduction of ocular artifacts, applied to the P300 ERP. Psychophysiology, 23, 695-703.

Taylor, J. R., Buratto, L. G., \& Henson, R. N. (2013). Behavioral and neural evidence for masked conceptual priming of recollection. Cortex, 49, 1511-1525.

Taylor, J. R., \& Henson, R. N. (2012). Could masked conceptual primes increase recollection? The subtleties of measuring recollection and familiarity in recognition memory. Neuropsychologia, 50, 3027-3040.

Tunney, R. J., \& Fernie, G. (2007). Repetition priming affects guessing not familiarity. Behavioral and Brain Functions, 3, 40-46.

Voss, J. L., \& Federmeier, K. D. (2011). FN400 potentials are functionally identical to N400 potentials and reflect semantic processing during recognition testing. Psychophysiology, 48, 532-546.

Voss, J. L., \& Paller, K. A. (2009a). An electrophysiological signature of unconscious recognition memory. Nature neuroscience, 12, 349-355.

Voss, J. L., \& Paller, K. A. (2009b). Remembering and knowing: Electrophysiological distinctions at encoding but not retrieval. Neuroimage, 46, 280-289.

Voss, J. L., \& Paller, K. A. (2010). Real-time neural signals of perceptual priming with unfamiliar geometric shapes. The Journal of Neuroscience, 30, 9181-9188.

Voss, J. L., Schendan, H. E., \& Paller, K. A. (2010). Finding meaning in novel geometric shapes influences electrophysiological correlates of repetition and dissociates perceptual and conceptual priming. Neuroimage, 49, 2879-2889.

Wang, W., Li, B., Gao, C., \& Guo, C. (2018). The temporal dynamics of perceptual and conceptual fluency on recognition memory. Brain and Cognition, 127, 1-12.

Wang, W., Li, B., Gao, C., Xiao, X., \& Guo, C. (2015). Electrophysiological correlates associated with contributions of perceptual and conceptual fluency to familiarity. Frontiers in Human Neuroscience, 9, 1-11.

Wang, W., Li, B., Gao, C., Xu, H., \& Guo, C. (2015). Conceptual fluency increases recollection: behavioral and electrophysiological evidence. Frontiers in Human Neuroscience, 9, 1-11.

Westerman, D. L. (2008). Relative fluency and illusions of recognition memory. Psychonomic Bulletin \& Review, 15, 1196-1200.

Westerman, D. L., Lanska, M., \& Olds, J. M. (2015). The Effect of Processing Fluency on Impressions of Familiarity and Liking. Journal of Experimental Psychology: Learning, Memory, and Cognition, 41, 426-438.

Westerman, D. L., Lloyd, M. E., \& Miller, J. K. (2002). The attribution of perceptual fluency in recognition memory: The role of expectation. Journal of Memory and Language, 47, 607-617.

Westerman, D. L., Miller, J. K., \& Lloyd, M. E. (2003). Change in perceptual form attenuates the use of the fluency heuristic in recognition. Memory \& Cognition, 31, 619-629.

Whittlesea, B. W., Jacoby, L. L., \& Girard, K. (1990). Illusions of immediate memory: Evidence of an attributional basis for feelings of familiarity and perceptual quality. Journal of Memory and Language, 29, 716-732. 
Wolk, D. A., Schacter, D. L., Berman, A. R., Holcomb, P. J., Daffner, K. R., \& Budson, A. E. (2004). An electrophysiological investigation of the relationship between conceptual fluency and familiarity. Neuroscience Letters, 369, 150-155.

Woollams, A. M., Taylor, J. R., Karayanidis, F., \& Henson, R. N. (2008). Event-related potentials associated with masked priming of test cues reveal multiple potential contributions to recognition memory. Journal of Cognitive Neuroscience, 20, 11141129.

Yonelinas, A. P. (2002). The Nature of Recollection and Familiarity: A Review of 30 Years of Research. Journal of Memory and Language, 46, 441-517.

Yonelinas, A. P., \& Jacoby, L. L. (1995). The Relation between Remembering and Knowing as Bases for Recognition: Effects of Size Congruency. Journal of Memory and Language, 34, 622-643. 